Instituto Internacional de Investigación y Desarrollo Tecnológico Educativo INDTEC, C.A.

DOI: https://doi.org/10.29394/Scientific.issn.2542-2987.2018.3.7.11.211-230

OAI-PMH: http://www.indteca.com/ojs/index.php/Revista Scientific/oai

\title{
Transformación del Docente desde el Pensamiento Complejo
}

\author{
Autora: Johana Carolina Peña Lozada \\ Escuela Técnica Robinsoniana y Zamorana "Monseñor Estanislao Carrillo", ETRZMEC \\ johanacarol@yahoo.com \\ Trujillo, Venezuela
}

\section{Resumen}

El presente artículo es una indagación cualitativa de paradigma fenomenológico interpretativo, de tipo documental; y se busca analizar la transformación del docente desde el pensamiento complejo, centrado en el beneficio docente-estudiante, a través de una triangulación documental bibliográfica de los autores Edgar Morín y Matthew Lipman con el tema del pensamiento complejo y los saberes necesarios para la educación, David Ausubel, Jean Piaget y Lev Vygotsky con la psicología educativa, Pérez Esclarín con la humanización de la educación, y por último con aportes de Honore Bernard, la UNESCO en materia de transformación docente. Ante la crisis y la evolución de la educación en América Latina se requiere de una reforma educativa donde se contemple la innovación, creatividad, formación, vocación y amor de las prácticas docentes, mirando hacia el perfil de ajuste de la realidad actual de los aprendices, asumiendo de manera continua el reto de romper barreras que obstruyen la meta que se persigue en el campo multidimensional, profesional, espiritual y humano, sumergido en la complejidad de su quehacer, e interaccionando con todos los elementos interiores y exteriores de su humanidad que están expuestos en el desafío del pensamiento complejo.

Palabras clave: profesor especializado; enseñanza profesional; pensamiento.

Fecha de Recepción: 08-05-2017 Fecha de Aceptación: 28-10-2017 


\section{Teacher Transformation from Complex Thinking}

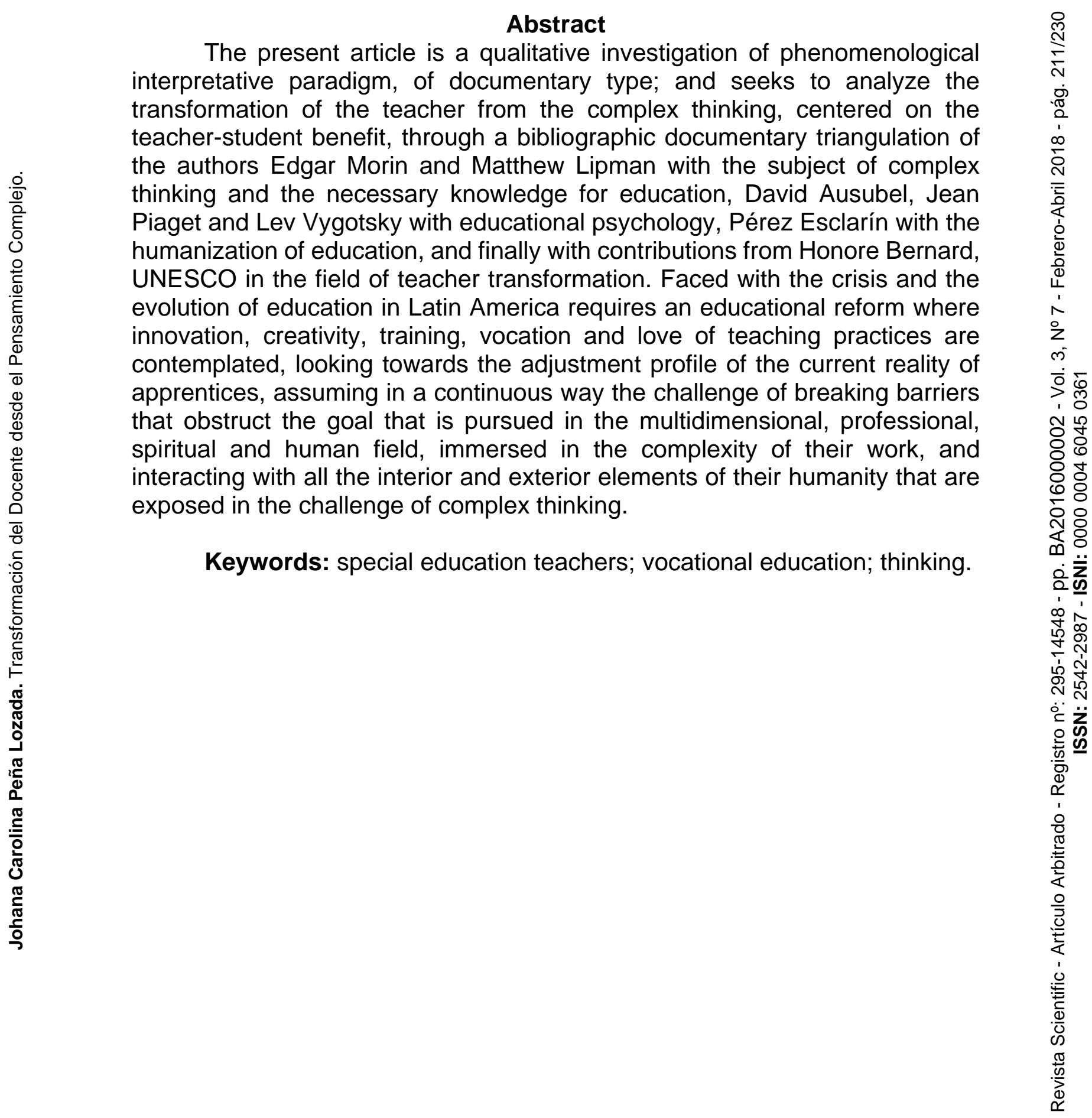

Date Received: 08-05-2017

Date Acceptance: 28-10-2017 


\section{Introducción}

América latina como mundo globalizado en su variedad de exponentes económicos, políticos, educativos, culturales y problemas familiares, diversos autores emblemáticos sostienen que la educación con todo y sus problemas viene siendo la solución a estas dificultades; por tanto, urge un aprendizaje basado en valores, con una formación humanista e instrucción del pensamiento. Aunado a lo anterior, se ha de considerar hombres con conciencia, con razonamientos lógicos donde sean idóneos para analizar, interpretar, construir el conocimiento y resolver los problemas que pertenecen a su realidad.

Todo pues, con miras a una educación transformadora del siglo XXI. Entendiendo por transformación no a lo indicado por el Diccionario de la Lengua Española como: "Acción y efecto de transformar" (pág. s.n.). Sino a lo que dispone Wikipedia, la enciclopedia libre, es decir "a la acción o procedimiento mediante el cual algo se modifica, altera o cambia de forma manteniendo su identidad" (pág. s.n.). De allí que la Transformación Educativa está orientada por algunas líneas comunes entre las cuales se destaca la prioridad otorgada a la reforma institucional de los Sistemas Educativos y de acuerdo con la Gestión de la Transformación Educativa (2013), serían:

La descentralización autonómica de las escuelas, instalación de sistemas de evaluación de resultados, el impulso de programas compensatorios focalizados a determinada población - meta, la modernización de los sistemas de información para la gestión, los cambios en las modalidades de financiamiento educativo, la búsqueda de una mayor participación de los miembros de la comunidad y la movilización de todos los actores de la sociedad en torno a los procesos educativos (pág. 66).

Considerando lo antes expuesto, en materia de transformación educativa, la UNESCO (1970), establece que "dentro de la problemática planteada de un sistema educacional en América Latina debe realizarse una 
reforma educativa, con una visión a obtener una educación de calidad" (pág. 8). En este sentido la trasformación del pensamiento se hace fundamental, pero no sin antes hacer estas preguntas: ¿Está la educación en la actualidad en condiciones para ser modelo en valores para formar al individuo del siglo XXI?, ¿se puede concientizar al Docente para que su transferencia de conocimiento sea significativa?, ¿Qué vínculos puede articular el docente en su praxis educativa con los siete saberes para la educación del futuro de Edgar Morín?

De lo anteriormente señalado, se puede entender, que hay una crisis en la educación, que no puede solventarse de un momento a otro. El saber educativo no puede cambiar sin transformaciones profundas en la educación y ésta resulta ineficiente sin un cambio pro activo en el pensamiento y en la práctica docente, siendo imperativo emprender acciones transformadoras en el ámbito formativo fragmentando el todo en sus partes y relacionando sus partes con el todo dentro del marco de la complejidad de lo complejo, lo que amerita cambios en los esquemas que los docentes han manejado hasta la actualidad, donde ellos son los únicos dueños del saber y los alumnos sus discípulos, además de ocasionar el aislamiento de la institución con la realidad social en que se encuentran inmersos sus estudiantes.

Ahora bien, lo que se pretende es un proceso donde el estudiante sea tomado en cuenta desde todas sus dimensiones y capacidades, sin aislarlo de su ambiente social, sino que éste sirva como principio para su aprendizaje, desde la vivencia real, al compartir ideas y experiencias entre docentes y estudiantes, pudiéndose lograr un aprendizaje significativo tanto para el docente como para los estudiantes. De las tres interrogantes planteadas surge con relación a estas, el mejoramiento continuo por lo que debe pasar todo profesional de la docencia para entrar en sincronía con el espacio tiempo en su incesante transformación. Y de acuerdo Ausbel (1918-2008), citado en las Teorías de la Educación de Sabori (2009), debe entenderse por aprendizaje 
significativo:

De acuerdo con el aprendizaje significativo, los nuevos conocimientos se incorporan en forma sustantiva en la estructura cognitiva del alumno. Se logra cuando el estudiante relaciona los nuevos conocimientos con los anteriores adquiridos; pero es necesario que el alumno se interese por aprender lo que se le está mostrando. (pág. s.n.).

Ramos (2014a), sostiene que para Lev Vygotsky (1896-1934), en cambio los niños construyen su propio entendimiento, que no reproducen pasivamente lo que se les presenta; "sino que la construcción cognitiva está mediada socialmente está siempre influida por la interacción social presente y pasada; lo que el maestro le señala al alumno influye en lo que este construye" (pág. 8). Para Piaget (1896-1980), quien es citado por Ramos (2014b), acumuló pruebas que sostienen un nuevo modo de comprender la evolución de la inteligencia: el constructivismo:

La inteligencia no comienza ni por el conocimiento del "yo" ni por el de las cosas en cuanto a tales, sino por el de su interacción, y orientándose simultáneamente hacia los dos polos de esta interacción, la inteligencia organiza al mundo, organizándose a sí misma. Su visión del constructivismo lo pone en oposición a ideas estructuralistas de gran impacto durante el siglo XX. (pág. 9).

En este aprendizaje significativo y en el constructivismo debe tener participación el docente. Y si bien es cierto, que la formación docente compete a todas las personas que laboran en el ámbito educativo, pues los mismos deben buscar formarse, o si ya están formados que dicha formación sea entendida como una actividad constante, guiada al mejoramiento del nivel de enseñanza de los docentes, tema imprescindible para su formación futurista, dada la diversidad de profesionales que intervienen en los procesos educativos a nivel de media general en el aprendizaje significativo y en el constructivismo. 
Así, los antes mencionados obtendrán conocimientos pedagógicos y didácticas innovadoras para la transformación en el aprendizaje del estudiante. De acuerdo con esta temática, Honore, (1980), establece que "La Formación concierne al porvenir del hombre, ya sea como producto, proceso o elemento articulador de otros conceptos y prácticas, tiene relación con la globalidad de experiencias obtenidas del sujeto" (pág. 176). Y Bello (2014a), entiende por Formación Permanente como: "El derecho y obligación de los educadores, así como de las autoridades administrativas de la educación, para garantizar una actualización continua de los profesores y maestros" (pág. 66). Y por docente Bello (2014b), entiende que:

Será quien garantice la máxima calidad de los procesos de enseñanza-aprendizaje. Será aquel que velará por la correcta adecuación de los contenidos. Atenderá a las necesidades de los estudiantes, supervisará, seguirá y evaluará el proceso de aprendizaje de éstos. En la actualidad, se prefiere regresar al concepto de educador. (pág. 43).

A este respecto, se puede concebir que todo acto de formación deba estar abierto a constantes renovaciones donde sea beneficiado en cuanto a los procesos y productos que se relacionen con su constante mejora pedagógica y sean cúmulo de prácticas que vayan alimentando su praxis didáctica, en constante aprendizaje dirigido hacia la transformación de su formación docente. Asimismo, para Díaz, (1988): "La formación hace referencia a un proceso más amplio que debe insertarse en lo reflexivo, en el conocimiento de campos del saber que dan cuenta de lo educativo: la filosofía, psicología, pedagogía" (pág. 176).

En efecto, formarse adecuadamente significa reflexionar sobre to aprendido en los distintos campos del saber para trasmitir conocimientos a los estudiantes que vayan acordes con realidades cónsonas para lograr su transformación. De ahí, la importancia del presente trabajo donde se busca analizar la transformación del docente desde el pensamiento complejo. 


\section{El Docente Innovador}

La práctica docente en este momento ha dado un giro de 180 grados, en este mundo cambiante la educación no escapa a esto, todo amerita cambios, las constantes capacitaciones, cursos, talleres, la innovación en la planificación educativa vienen a ser un incentivo de superación para la docencia a favor de lograr la calidad en los procesos de enseñanzaaprendizaje.

De hecho, se requiere de un docente innovador, que motive al educando, dándole las herramientas necesarias para que su aprendizaje sea significativo, es decir concienciándolo para que al transferir conocimientos esto sea específico. Tomando en consideración el enfoque constructivista que según Piaget (1981), Ausubel (1993) y Vygotsky, (1979), quienes son citados por Ramos (2014c), "el aprendizaje es un proceso de construcción de conocimiento individual, significativo y social" (pág. 9).

Dentro de este contexto, la formación y actualización constante del docente, es considerada como una herramienta que busca la instrucción conforme en el desarrollo del estudiante; este tipo de actualización, se promueve mediante dos vías, una se da en base a los colectivos institucionales, diseñados de forma directa y participativa integrando todos los perfiles profesionales al uso y aplicación de todas las mecánicas estructurales de un programa pedagógico; la otra es el docente investigador, propagador de ideas que satisfagan las necesidades cognitivas y formativas, así como las actitudinales, todas ellas inherentes al perfil idóneo del docente.

En todo caso hay que formar para transformar, por ello se hace pertinente la formación continua del docente, que se instruya y que se oriente en cursos, talleres que sean de crecimiento profesional, humano, en valores. Ayudando al alumno en su conocimiento, que lo guíe, apoye y se identifique con los problemas e inconvenientes del mismo, que no lo ayudan a surgir y ser mejor persona. Así mismo, no se debe pensar solo en el proceso de 
enseñanza-aprendizaje, sino en el aspecto del ser humano, como persona, basado en una educación integral y formándolo para educarlo para la vida en función de los términos de su propia realidad. En cuanto a los valores, Pérez (2012), manifiesta que:

Es genuino educador no aquel que sabe mucho o tiene una serie de títulos y postgrados, sino aquel que es capaz de despertar la curiosidad de sus alumnos y provoca en ellos el hambre de aprender, de descubrir, de crecer, de vivir a plenitud. No les comunica tanto sus conocimientos, sino sus deseos y habilidades para que ellos los adquieran. Vive con sus alumnos la aventura del aprendizaje cotidiano, convierte su salón en un taller, en un laboratorio, en un lugar de búsqueda, de encuentro y convivencia, de construcción de nuevos conocimientos. Todo esto solo será posible si el educador tiene ganas de aprender, es un enamorado de la vida y de la enseñanza, está comprometido en su continua formación y crecimiento, para de ese modo, ayudar al crecimiento de sus alumnos. (pág. 144).

A tal efecto el mismo Pérez (2004), apunta: "La formación adecuada del educador supone un cambio radical para transformarlo de consumidor de cursos y repetidor de conocimientos problemas que le plantea la práctica" (pág. 22). En otras palabras, la transformación del docente, en la actualidad amerita que éste sea innovador, investigador, transformador, capaz de implementar estrategias, actividades para incentivar al estudiante transfiriéndole el conocimiento de manera competente, abierto al cambio, retirando en su mayoría de espacio lo tradicional, escuchando las opiniones de sus aprendices, todo dirigido a su transformación abierta al devenir pedagógico posmoderno que se avizora en estos tiempos de cambio.

\subsection{Docencia e Investigación hacia la Transformación Curricular.}

Diversos han sido los enfoques que han atribuido diferentes papeles al docente con respecto al tipo de vinculación que debe tener con la investigación educativa. En este momento coexisten posiciones que van desde su ubicación 
como un ente pasivo dentro de este proceso, hasta los que plantean que su rol es el de principal protagonista, sin contar con las posiciones intermedias entre estas dos posturas extremas.

Entre tanto, en este caso se concibe a la educación como objeto de diferentes ciencias y el docente como consumidor de Investigaciones. Algunos autores, como (Gimeno, 1986a: pág. 16) y (Stenhouse, 1987a: pág. 97) sostienen que la educación ha sido objeto de conocimiento de disciplinas subsidiarias que en su conjunto se le ha denominado las Ciencias de la Educación. Estos autores sostienen que precisamente debido a lo anterior ha habido poco desarrollo de la teoría particularmente educativa, es decir, de la teoría que surge y se relaciona con la práctica de la educación.

A las investigaciones realizadas desde disciplinas subsidiarias de las Ciencias de la Educación, ambos autores las denominan investigaciones sobre educación para diferenciarlas de las investigaciones en educación o educativas, las cuales son realizadas según, Stenhouse (1987b), dentro del proyecto educativo y enriquecedoras de la empresa educativa "esta realidad trae consigo consecuencias con respecto al papel que debe cumplir el docente en el proceso de la investigación sobre la educación" (pág. 42).

No obstante, el docente como Investigador y propulsor de la transformación y el cambio social, se ha desarrollado una tendencia de pensamiento que coloca al docente como un ente, el cual, por su posición estratégica en el marco de las relaciones sociales, es un factor de primera línea para propiciar el cambio social. Esta línea del pensamiento se encuentra en América Latina, desde la primera mitad de los años 50, en esos años el maestro Luís Beltrán Prieto sostenía que, desde la concepción que vincula a la Escuela con la Comunidad, al maestro como servidor social le han surgido nuevas responsabilidades, le corresponde trabajar en la detección de las necesidades de la comunidad para lograr solventarlas con la cooperación de éstas, (Prieto: 1955a, pág. 49). 
Así el maestro se convertiría en un auténtico líder de la comunidad y según el autor Prieto (1955b), tal posibilidad supone, que "los maestros deben hacer investigaciones sobre las características más resaltantes de la comunidad donde va a trabajar, requiriendo para ello de la aplicación de Técnicas de Investigación Apropiadas" (pág. 50). Parafraseando al citado autor, hoy una de las competencias del docente es la de ser promotor comunitario, pues debe trabajar mancomunadamente para detectar de cerca las realidades de su entorno, para llevar a cabo la transformación en el currículo de este milenio.

Ante tales planteamientos, es necesario cultivar un campo científico prácticamente sin hacer, que según Gimeno, (1986b), establece desde esta perspectiva, se revaloriza la necesidad de asumir el contexto del "aula y el proceso de enseñanza-aprendizaje como centro de estudio y reflexión..., está claro que una de las grandes desconexión con la realidad del aula, es su falta de comprobación en la acción" (pág. 48).

Precisamente, observando lo dicho por el autor antes señalado, hay poco impacto en las investigaciones educativas, producto de no haberse generado desde la realidad de las aulas de clase, sino en situaciones artificiales y descontextualizadas del quehacer diario de la docencia. Como se aprecia, de esta tendencia que pone énfasis en la investigación en el aula, es que hubo la inquietud de la autora de escribir sobre la temática de la transformación en el docente debido a que han surgido diferentes posiciones en torno al papel que debe jugar el educador en el proceso de la investigación, la cual supone que la producción del conocimiento objetivo ha de depender de la observación de los hechos mensurables a través de métodos y técnicas diseñadas para tal fin.

\subsection{Pensamiento Complejo en Educación.}

Comenzar a transitar a través del pensamiento complejo, exige sin duda 
hacer alusión a Morín (2003a), destacado filósofo y político que plantea lo siguiente: "vivimos bajo el imperio del paradigma de la simplificación, de la disyunción, reducción y abstracción" (pág. 96). Es de inferir que el autor propone tomar conciencia de estos paradigmas que mutilan el conocimiento desfigurando lo real, para esto plantea la teoría de la complejidad a la que define como: "un tejido de constituyentes heterogéneas inseparablemente asociadas: presenta la paradoja de lo uno y de lo múltiple, visto de esta forma como el tejido de eventos, acciones, retroacciones, determinaciones, azares, que constituyen nuestro mundo fenoménico" (pág. 110).

En ese sentido, indica Paredes (2013a), que el Postmodernismo, a diferencia de la Modernidad, representado por el conocimiento simplificador, determinista y reduccionista; resalta aquello que ha sido marginado del conocimiento científico: "las emociones, las pasiones, en fin, los aspectos irracionales del hombre; busca nuevos estilos discursivos donde el lenguaje literario, científico y filosófico se alternen al unísono potenciando el significado de las palabras" (pág. 34). Ese determinismo mecánico tiene que dar paso y aprender la complejidad de lo real. Paredes denuncia el determinismo y reduccionismo: "ya no es posible comprender el mundo desde metadiscursos como el marxismo, el psicoanálisis o el positivismo, pues éste escapa o se rehúsa a ser definido por estos criterios" (Paredes, 2013b, pág. 34.).

La teoría de la complejidad y el pensamiento complejo intenta articular dominios disciplinarios a favor del docente del futuro, quebrados por el pensamiento disgregador y aspira al conocimiento multidimensional. Pabón y Serrano (2011a), ante esa situación del conocimiento parcelado, disgregado por el determinismo, se preguntan: ¿Qué es el paradigma de la complejidad?, (pág. 647). Y se responden señalando que:

Es un valor integrador y holístico de percibir, pensar y valorar un fenómeno. Concibe el conjunto de componentes heterogéneos inseparablemente unidos, que presenta la paradójica relación de lo uno y lo múltiple, de un fenómeno. 
Constituye un tejido de eventos, acciones, interacciones, determinaciones, azares que integran y constituyen nuestro mundo fenoménico. (Pabón y Serrano, 2011b, págs. 647- 648).

De allí que Morín (2003b), indica que el pensamiento complejo: "Es la capacidad de interconectar distintas dimensiones de lo real. Promueve un enfoque transdisciplinario y holístico, sin abandonar la noción de las partes constituyentes del todo" (pág. 15). La teoría de la complejidad capta la realidad como sistema complejo, en sus diversas conexiones, mediaciones y condicionamientos. Por eso no establece relaciones antitéticas entre orden y caos, incertidumbre y certidumbre, entre las partes y el todo. Si no lo asume teniendo conciencia de que son antitéticas, cada uno por separado, pero a la vez, los unifica, sin convertirlos en un todo, cada elemento conserva su identidad y unidad.

Ahora bien, la formación del docente hacia la transformación requiere aprobación especializada, posiblemente de carácter pedagógico, es necesario considerar que las políticas institucionales, el aseguramiento de la calidad que potencie aquellas que promuevan el desarrollo profesional del docente, a lo largo de su carrera, por ello, dado que en este momento las universidades deben desarrollar un escenario orientado a potenciar la formación pedagógica y el desarrollo profesional del profesorado como una estrategia fundamental para mejorar la calidad de la enseñanza. El docente en su práctica cotidiana, integra distintos saberes desde esta perspectiva, el saber docente está formado por una mixtura más o menos coherente de saberes curriculares y experienciales.

Estas consideraciones según investigadores como García (2007), señala que "la práctica docente no sólo es un objeto del saber de las ciencias de la educación sino también una actividad que teoriza, diversos saberes que pueden llamarse pedagógicos, los cuales se presentan como doctrinas por la práctica educativa" (pág. 57). Ampliando el término, las reflexiones personales 
y normativas conducen al sistema, más o menos coherente en los saberes pedagógicos en representación de la actividad educativa.

En este sentido, los saberes pedagógicos se articulan con las ciencias de la educación formando redes o nudos, que denotan puntos de interacción y determinan la interrelación de los componentes inmersos en el sistema, en este caso el saber pedagógico. Ahora bien, desde la práctica docente, se logra un saber hacer para determinar en la cotidianidad para ser producido por las ciencias de la educación y los saberes pedagógicos, las prácticas docentes incorporan también unos saberes especiales seleccionado por la institución educativa.

En este orden de ideas, Ugas (2008a), consideraba la educación en tres aspectos constituyentes del ser humano: "mente, corazón y brazos; vale decir: pensamiento, sentimiento y acción" (pág. 98). Por tanto, las ciencias al convertirse en materia de enseñanza generan las disciplinas, vale decir, la ciencia que se enseña. De ahí, que la educación de calidad es la que ofrece contenidos que el individuo necesita como persona intelectual, afectiva y moral, para desempeñarse adecuadamente en los diferentes ámbitos de la sociedad.

Por ende, el pensamiento complejo, según Morín, (2003c), se propone re articular "Ios conocimientos aplicando criterios o principios generativos y estratégicos del método; esos principios son: principio sistémico $u$ organizacional, principio hologramático, principio de retroactividad, principio de recursividad, principio de autonomía/dependencia, principio dialógico y principio de reintroducción del cognoscente en todo conocimiento" (pág. 131).

Al respecto, Ugas (2008b), parafraseando a Morín expresa "podemos decir que un programa educativo es una organización predeterminada de la acción que efectúa la repetición de lo mismo en lo mismo, es decir, necesita de condiciones estables para su ejecución" (pág. 98). Mientras, que una estrategia pedagógica es abierta, evolutiva, afronta lo imprevisto, lo nuevo. EI 
programa no improvisa ni innova, la estrategia si lo hace. El programa sólo experimenta una dosis débil de obstáculos en su desarrollo.

Al mismo tiempo, el pensamiento complejo en educación va más allá de la expresión enseñanza-aprendizaje, tomándose cada uno de estos procesos en fracciones separadas con un punto en común que sería la educación; es decir, “¿Cómo enseño?, ¿cómo aprendo?”; disociación ésta que desde ya delimita las parcelas del saber, además de abrir una brecha entre quién enseña "docente" único dueño del conocimiento y quién aprende "estudiante" el qué no sabe nada. Sintetizando, también se trasciende a la definición de educación como fenómeno social que da origen a la generación de las sociedades, porque se considera como la difusión de normas y costumbres en las nuevas generaciones.

Por esta razón se piensa que es importante una reestructuración del proceso educativo, que a decir de (Lipman: 1998, Pensamiento Complejo y Educación, pág. 55), quien es citado por Márquez y Martínez (2012a), donde la "educación sea el objetivo de la participación en una comunidad de indagación guiada por el profesor, entre cuyas metas estén la pretensión de comprensión y buen juicio" (pág. 266); es decir:

Una educación opuesta a la pasividad del educando, en donde todos intervengan activamente y el profesor sea capaz de admitir la diversidad de opiniones, la divergencia de criterios, la concordancia o no de los juicios con la verdad de la realidad, superando toda postura coercitiva, represiva o autoritaria a fin de permitir la libre expresión de los alumnos y su manera de ver y entender el mudo que los rodea. (Márquez y Martínez, 2012b, pág. 266).

Bajo estos paradigmas, es necesario reflexionar sobre el complejo significado de la educación; que no puede persistir siendo estimada desde la apariencia tradicional de la reducción, que implica la transmisión de normas, conocimientos, culturas, donde el sujeto se encuentra estático en el hecho 
educativo, y no es tratado como un ser pensante, creativo, participativo en la parte activa de la educación y la sociedad en que se desenvuelve; sino como un receptáculo vacío de conocimientos.

\subsection{La Educación como Proceso Innovador-Creativo y los Desafíos ante el Pensamiento Complejo.}

En un mundo de acelerados cambios, se descubre la necesidad de una nueva visión y un nuevo modelo de enseñanza, que su deber ser es estar centrado en el estudiante, lo cual exige docentes capacitados, con ética y vocación donde juntamente con los contenidos, estrategias, prácticas y medios de transmisión del conocimiento hacen amena la materia.

Vinculado al concepto Morín (2003d), plantea como retos sociales "los principios de conocimiento pertinente, enseñar la condición humana, lo global, relaciones entre el todo y las partes, comprensión, identidad terrenal con la incertidumbre con la ética del género humano y la ceguera del conocimiento" (pág. 43). Así como, ir de enfoques tradicionales a innovadores de procesos centrados en el docente, a una formación con centro en el estudiante, desde la formación inicial a la formación permanente.

En este caso, se busca que el estudiante interprete, analice, sea crítico reflexivo, que resuelva problemas e inconvenientes que se le presenten en el saber. Sobre la base de lo explicado, es imprescindible que las instituciones formen sujetos para que se conviertan en ciudadanos con responsabilidades sociales, para que alcancen el dominio cognitivo, adquiriendo conocimientos versados, analítico creativo y opinantes, que realice la reflexión emancipada y el trabajo en equipo en contextos multiculturales en los que la creatividad exige combinar el saber teórico y práctico conducido con una tecnología de avance inmersa en valores. 


\section{Conclusiones}

Se observa que, los docentes en la actualidad se encuentran bajo un constante bombardeo de información para lograr el verdadero reto educativo, inmerso con nuevas tecnologías y teorías que le obligan a mantenerse actualizados; para así poder llevar a cabo su labor de manera ordenada, con miras a su transformación.

Por esto, es imperativo un cambio del pensamiento y la praxis pedagógica porque para afrontar el acto de educar, no se puede prolongar en el modelo de la disyunción en que se es profesor de un área concreta y de ese límite no se sale, esto es un concepto errado de lo que significa ser educador. En este sentido, el tipo de educador encasillado en lo tradicional quedara rezagado si no rompe con su paradigma.

Además, no puede tener límites ante el proceso educativo siempre tiene que ir más allá en la búsqueda de los conocimientos e interconexiones de estos, partiendo desde las múltiples dimensiones del ser y de su contexto, no obstante, para poder llegar a esto, el docente tiene que conocer y practicar muy bien las suyas y de esta manera, podrá orientar y dirigir mejor a los demás que están a su alrededor, en este caso sus estudiantes.

Debe haber por parte del docente una revisión y reflexión interna, quien debe ser una persona con una mentalidad amplia para dar cabida a los cambios que se le presenten, además de ser un conocedor del contexto en que desarrolla su labor de educador, para poder concretar su praxis de forma significativa tanto para él, como para sus estudiantes de manera libre e integradora.

Asimismo, dentro de la complejidad de lo complejo, todo profesional de la docencia debe poseer una clara certeza de su vocación, de que quiere y tiene mucho que dar y brindar a la sociedad. Es un compromiso ante las comunidades, el dar sin egoísmos en un todo armónico y de confianza, estando abiertos ante cualquier intervención o sugerencia que surja en el 
desarrollo de las clases; así, en la medida en que exista un ambiente de apertura y confianza, se estará llevando a cabo la formación de personas autónomas, libres y solidarias. De allí que Chirinos (2014a), menciona que Sastre, J. (1996), expresa que el "término vocación viene del latín vocatio, que significa llamada; en consecuencia, la llamada puede ser acogida" (pág. 20). Indica que:

La vocación docente es una llamada especial que.... se ha hecho a determinadas personas para que contribuyamos, de manera específica, a desarrollar en cada niña, niño y jóvenes todos los contenidos y significados humanos que potencialmente ya existen en ellos... (Chirinos, 2014b, pág. 20).

En resumidas cuentas, para lograr que el docente se identifique con su labor y se enamore de la misma, se hace necesario asumir una gran concientización desde las aulas de clase y de su interior como docente, para que de ésta manera los jóvenes se encuentren plenamente motivados y enamorados de sus contenidos, de la materia, además de contar con una excelente preparación, académica, humana y espiritual que les permita desempeñarse con facilidad en el puente didáctico de la enseñanza y de forma placentera, en otras palabras, que amen lo que están haciendo por sus estudiantes y la sociedad; el resto vendrá por añadidura.

\section{Referencias}

Bello, J. (2014a,b). Diccionario de Educación. Caracas: Editorial Panapo. Chirinos, M. (2014a,b). Vocación Docente. San Pablo. Caracas: Talleres Escuela Técnica Don Bosco.

Díaz, A. (1988). Investigación educativa y formación de profesores. En Investigación educativa y formación de profesores. Contradicciones de una articulación. Cuadernos del CESU, número 20, México: UNAM. 
Diccionario de la Lengua Española (2014). Transformación. [Diccionario en línea]. Recuperado de: http://dle.rae.es/?id=aJYQUV5

García, J. (2007). Estructura Organizativa de la Educación en Venezuela.

Tesis para optar al título de doctor. Maracaibo, Venezuela: Universidad Rafael Urdaneta.

Gestión de la Transformación Educativa (2013). Requerimiento de aprendizaje para las Instituciones. Serie de publicaciones IIPEBuenos Aires. Instituto Internacional de Planeamiento de la Educación. Informe del Foro IIPE-UNESCO, Buenos Aires, 16 al 18 de marzo del 2013.

Gimeno, S. (1986a,b). Planificación de la Investigación Educativa y su impacto en la Realidad. Caracas, Venezuela: En cuadernos de Educación, Nro. 129.

Honore, B. (1980). Para una Teoría de la Formación. Dinámica de la normatividad. Madrid: Narcea, S.A., Ediciones Madrid.

Márquez, A., \& Martínez, L. (Comps). (2012a,b). Lectura, ciudadanía y educación. Miradas desde la diferencia. Autores: Filosofía, Aprendizaje y Experiencia Estética. Un Enfoque Desde la Filosofía para Niños y Niñas de Matthew Lipman. Caracas, Editorial el Perro y la Rana. Morín, E. (2003a,b,c,d). Introducción al Pensamiento Complejo. Barcelona, España: Gedisa, S.A.

Pabón, A., \& Serrano, S. (2011a,b). Aprendizaje Universitario desde el Paradigma de la Complejidad. Educere. Revista Venezolana de la Educación. Año 15. No 52. Mérida: Talleres Gráficas de Producciones Editoriales, C.A.

Paredes, G. (2013a,b). Críticas Epistemológicas y Metodológicas a la Concepción Positivista en las Ciencias Sociales. Revista Académica, vol. 6, número. 12. Mérida, Venezuela.

Pérez, A. (2012). Para Educar Valores. Nuevas Parábolas. Talleres Técnica 
Don Bosco. Caracas: Ediciones San Pablo.

Pérez, A. (2004). Educar para Humanizar. Madrid España: Nancea, S.A.

Prieto, L. (1955a,b). "El Concepto de Líder, el Maestro como Líder". Caracas: Editorial Monte Ávila.

Ramos, E. (2014a,b,c). La Ruta del Pensamiento Crítico. Tesis Doctoral para optar al Título de Doctor en Ciencias de la Educación, Maracaibo, Venezuela: Universidad Rafael Belloso Chacín (URBE).

Sastre, J. (1966). EI Discernimiento Vocacional. Madrid: Editorial San Pablo. Stenhouse, L. (1987a,b). “Investigación y Desarrollo del Currículo”. Madre España: Editorial Morata.

Sabori, L. (2009). Teorías de la Educación. [Documento en línea]. Recuperado de: http://teoriasunikino.blogspot.com/

Ugas, G. (2008a,b). La Complejidad un Modo de Pensar. Venezuela. Ediciones del Taller Permanente de Estudios Epistemológicos en Ciencias Sociales. Segunda Edición.

UNESCO (1970). Seminario sobre el Papel de la Enseñanza Agrícola en el Desarrollo Rural: Algunos Modelos de Universidades para el Desarrollo de América Latina. Turrialba. Costa Rica, del 12-25 de octubre, pág. 8.

Wikipedia (s.f.). Transformación. [Documento en línea]. Recuperado de: https://es.wikipedia.org/wiki/Transformacion 


\section{Johana Carolina Peña Lozada \\ e-mail: johanacarol@yahoo.com}

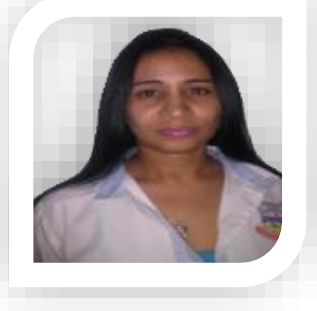

Nacida en la ciudad de Valera, Venezuela. Licenciada

Trujillo). Especialista en Gerencia de Recursos Humanos (Universidad Nacional Experimental Simón Rodríguez). Actualmente presentando Tesis en Doctorado en Educación en la Universidad Experimental Rafael María Baralt (UNERMB). Docente de Aula en la Escuela Técnica Salesiana Santo Tomas de Aquino. (Valera). Docente de Aula. Coordinadora de Planificación y Evaluación. Coordinadora de la Especialidad Comercios y Servicios Administrativos. Subdirectora Técnica en la Escuela Técnica Robinsoniana Zamorana Mons. Estanislao Carrillo (ETRZ. Mons. E C), ubicada Municipio San Rafael de Carvajal del Estado Trujillo.

El contenido de este manuscrito se difunde bajo una Licencia de Creative Commons Reconocimiento- 